\begin{tabular}{|c|c|c|}
\hline \multirow{3}{*}{$\begin{array}{r}\text { Case Reports in } \\
\text { Gastroenterology }\end{array}$} & \multirow{2}{*}{\multicolumn{2}{|c|}{ Case Rep Gastroenterol 2015;9:44-48 }} \\
\hline & & \\
\hline & $\begin{array}{l}\text { DOI: 10.1159/000376608 } \\
\text { Publisned online: February 10, } 2015\end{array}$ & $\begin{array}{l}\text { ( } 2015 \text { S. Karger AG, Basel } \\
\text { 1662-0631/15/0091-0044\$39.50/0 } \\
\text { www.karger.com/crg }\end{array}$ \\
\hline & \multicolumn{2}{|c|}{$\begin{array}{l}\text { This is an Open Access article licensed under the terms of the Creative Common } \\
\text { Attribution-NonCommercial } 3.0 \text { Unported license (CC BY-NC) (www.karger.com/OA } \\
\text { license), applicable to the online version of the article only. Distribution permitted for non } \\
\text { commercial purposes only. }\end{array}$} \\
\hline
\end{tabular}

\title{
A Unique Case of a Patient with Rectal Cancer Who Developed Benign Esophageal Stenosis after Localized Rectal Radiation and Systemic Chemotherapy
}

\author{
Elie Chahla ${ }^{\mathrm{a}}$ Antonio Cheesman ${ }^{\mathrm{b}} \quad$ Muhammad Hammami $^{\mathrm{a}}$ \\ Jason R. Taylor ${ }^{a} \quad$ Nishant Poddar ${ }^{c}$ Robert W. Garrett ${ }^{d}$ Samer Alkaade ${ }^{a}$ \\ ${ }^{a}$ Division of Gastroenterology and Hepatology, ${ }^{b}$ Department of Internal Medicine, \\ 'Division of Hematology and Oncology and d Department of Radiology, Saint Louis \\ University School of Medicine, St. Louis, Mo., USA
}

\section{Key Words}

Rectal cancer · Benign esophageal stenosis · Localized rectal radiation · Systemic chemotherapy

\begin{abstract}
Acute esophagitis and esophageal strictures typically occur after local radiation therapy to the thoracic field. Toxicity is usually limited to the field of radiation and potentially augmented by concomitant use of chemotherapy, however esophageal stricturing due to chemotherapy alone is exceedingly rare. Gastrointestinal toxicity has been previously reported in the setting of 5-fluorouracil (5-FU)-based chemotherapy with abnormal thymidylate synthase or dihydropyrimidine dehydrogenase activities. We present a unique case of isolated chemotherapy-induced esophageal stricture in the setting of stage IIIa rectal adenocarcinoma which presented shortly after initiation of treatment with 5-FU-based chemotherapy in a patient with normal thymidylate synthase and dihydropyrimidine dehydrogenase assays. These findings prompt further investigation of pathways and potential risk factors leading to esophageal toxicity in patients treated with 5-FU-based chemotherapy. $\quad$ @ $2015 \mathrm{~S}$. Karger AG, Basel
\end{abstract}

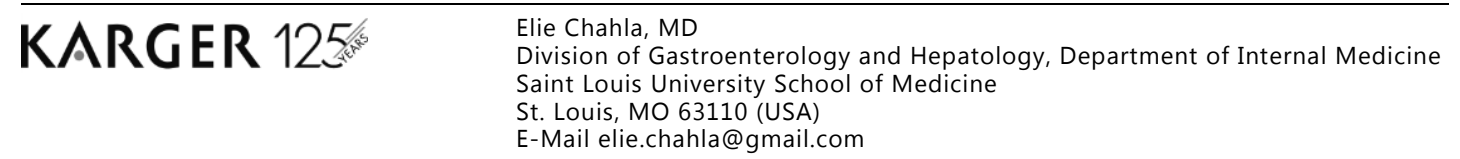




\section{Introduction}

Acute esophagitis and esophageal strictures are relatively common adverse effects related to radiation therapy in the setting of head, neck and thoracic malignancies with an incidence rate ranging from 22 to $37 \%$ [1]. Toxicity is usually dose-dependent [2-4], occurs within 2-3 weeks after the initiation of radiation therapy and is primarily related to disruption of the basal epithelial layer of the esophagus [5]. Subsequent inflammation and scar formation within the esophageal muscularis result in stricture formation, typically seen 3-6 months after completion of radiotherapy $[6,7]$. Esophageal strictures secondary to radiation therapy are usually located within the field of radiotherapy and potentially augmented by concomitant use of chemotherapy. However, esophageal strictures due to isolated chemotherapy use are extremely rare [8]. To our knowledge, only one case of isolated chemotherapy-induced esophageal stricture has been reported in the adult population, involving a patient with acute myelogenous leukemia [9]. No cases have been identified while undergoing adjuvant chemotherapy for solid tumors. We present the case of a patient receiving adjuvant chemotherapy for rectal cancer who subsequently developed a benign but severe recurrent esophageal stricture.

\section{Case Report}

A 55-year-old female was diagnosed with stage IIIa (cT2N0M0, uT2N1M0) rectal adenocarcinoma. She was treated with neoadjuvant chemotherapy with capecitabine $(1,250 \mathrm{mg} /$ $\mathrm{m}^{2}$ twice daily, days 1-14 of cycle) and localized radiation therapy (50.4 Gy in 28 fractions) to the rectum for 2 months. She subsequently underwent laparoscopic-assisted rectal resection, with pathology revealing moderately differentiated adenocarcinoma with negative margins, colonic J-pouch with diverting ileostomy, and adjuvant chemotherapy with modified FOLFOX-6 (oxaliplatin $85 \mathrm{mg} / \mathrm{m}^{2}$, 5-fluorouracil [5-FU] bolus $400 \mathrm{mg} / \mathrm{m}^{2}$, leucovorin $400 \mathrm{mg} / \mathrm{m}^{2}$ and 5 -FU infusion $1,200 \mathrm{mg} / \mathrm{m}^{2} /$ day for 2 days) for 2 cycles.

Three weeks after initiation of adjuvant chemotherapy, the patient was hospitalized for management of new-onset dysphagia and odynophagia. Her symptoms persisted despite discontinuation of chemotherapy and empirical treatment with antifungal therapy for suspected Candida esophagitis. An esophagogram and a computed tomography (CT) of the chest revealed irregular long narrowing in the mid and distal esophagus (fig. 1, fig. 2). Upper endoscopic evaluation revealed an 11-cm-long esophageal stenosis with mucosal erythema and friability starting $25 \mathrm{~cm}$ from the incisors (fig. 1). Repeat biopsies and imaging studies failed to reveal an infectious or neoplastic etiology. The patient had no history of dysphagia prior to adjuvant chemotherapy and during the period when she received neoadjuvant concurrent chemotherapy and radiation, and her esophagus had been normal-appearing on two previous CT scans performed 2 months before adjuvant chemotherapy administration. The patient's symptoms improved after endoscopic dilation therapy, but she required repeated endoscopic therapy on a monthly basis including intralesional steroid injections. A fully covered esophageal stent was placed twice with short-term improvement in symptoms. Unfortunately, the patient also had secondary development of new esophageal strictures at the proximal and distal ends of the stent. The esophageal stents were ultimately removed and the patient's symptoms were controlled with repeat endoscopic dilation of the benign stricture every 4-6 weeks. She had no evidence of esophageal malignancy on repetitive endoscopy with multiple biopsies or cross-sectional imaging for 18 months since diagnosis, further confirming the benign process. 
Chahla et al.: A Unique Case of a Patient with Rectal Cancer Who Developed Benign

Esophageal Stenosis after Localized Rectal Radiation and Systemic Chemotherapy

\section{Discussion}

Esophageal strictures are a known complication of radiation therapy especially during treatment of head, neck and thoracic malignancies. Injury to the esophagus results in severe fibrosis, mucosal atrophy, ischemic ulcerations and esophageal strictures [10, 11]. Isolated chemotherapy-induced esophageal strictures are a very rare entity and have only been described in the pediatric literature, specifically in the management of acute leukemias. Yata et al. [9] reported the only other existing case in adults, pertaining a 41-year-old woman who developed a 6 -cm-long lower esophageal stricture 12 days after re-induction therapy for acute myelogenous leukemia.

Our patient received 28 sessions of low-dose localized radiation therapy to the rectum with concurrent neoadjuvant capecitabine chemotherapy without any gastrointestinal complications. Esophageal toxicity and stricturing did not occur until systemic adjuvant chemotherapy with modified FOLFOX-6 (oxaliplatin, 5-FU bolus and leucovorin) was provided. It is highly unlikely that localized radiation therapy to the rectum would be responsible for the esophageal findings described.

Severe gastrointestinal toxicities of 5-FU-based chemotherapy can be more pronounced in patients with evidence of polymorphisms in the thymidylate synthase (TS) or dihydropyrimidine dehydrogenase (DPD) genes [12]. Low levels of TS expression are associated with toxicity to 5-FU. When DPD enzyme activity is low, the gastrointestinal mucosal involvement can be severe and, in rare cases, fatal. Surprisingly, our patient's DPD and TS enzymatic activity levels were both within normal limits.

Esophageal strictures secondary to isolated use of systemic chemotherapy are an exceedingly rare complication. We suspect that this unexpected but dramatic adverse event is caused by mucosal damage limited to the esophagus due to the chemotherapeutic agents, since our patient did not receive localized radiation to the esophageal field.

In conclusion, we report a very unusual and rare case of acute gastrointestinal toxicity limited to the esophagus after initiation of systemic oxaliplatin and 5-FU-based chemotherapy in a patient with normal TS and DPD assays. The possibility of other genetic mutations leading to this complication should be further investigated in future studies.

\section{References}

1 Lawson JD, Otto K, Grist W, Johnstone PA: Frequency of esophageal stenosis after simultaneous modulated accelerated radiation therapy and chemotherapy for head and neck cancer. Am J Otolaryngol 2008;29:13-19.

2 Emami B, Lyman J, Brown A, Coia L, Goitein M, Munzenrider JE, Shank B, Solin LJ, Wesson M: Tolerance of normal tissue to therapeutic irradiation. Int J Radiat Oncol Biol Phys 1991;21:109-122.

-3 Morichau-Beauchant M, Touchard G, Battandier D, Maire P, Fontanel JP, Daban A, Babin P, Matuchansky C: Chronic radiation-induced esophagitis after treatment of oropharyngolaryngeal cancer: a little-known anatomo-clinical entity (in French). Gastroenterol Clin Biol 1983;7:843-850.

4 Seaman WB, Ackerman LV: The effect of radiation on the esophagus; a clinical and histologic study of the effects produced by the betatron. Radiology 1957;68:534-541.

5 Phillips TL, Ross G: Time-dose relationships in the mouse esophagus. Radiology 1974;113:435-440.

-6 O'Rourke IC, Tiver K, Bull C, Gebski V, Langlands AO: Swallowing performance after radiation therapy for carcinoma of the esophagus. Cancer 1988;61:2022-2026.

$\checkmark 7$ Coia LR, Myerson RJ, Tepper JE: Late effects of radiation therapy on the gastrointestinal tract. Int J Radiat Oncol Biol Phys 1995;31:1213-1236.

-8 Guadagnolo BA, Haddad RI, Posner MR, Weeks L, Wirth LJ, Norris CM, Sullivan CA, Goguen L, Busse PM, Tishler R: Organ preservation and treatment toxicity with induction chemotherapy followed by radiation therapy or chemoradiation for advanced laryngeal cancer. Am J Clin Oncol 2005;28:371-378. 
Chahla et al.: A Unique Case of a Patient with Rectal Cancer Who Developed Benign Esophageal Stenosis after Localized Rectal Radiation and Systemic Chemotherapy

-9 Yata K, Yamada O, Iwato K, Kyo T, Otsuki T, Nakanishi H, Suetsugu Y, Mikami M, Wada H, Yawata Y, Sugihara T: Acute myelogenous leukemia associated with severe esophageal stricture after chemotherapy (in Japanese). Rinsho Ketsueki 2002;43:41-43.

10 Kelly K, Storey L, O’Sullivan M, Butler K, McDermott M, Corbally M, McMahon C, Smith OP, O’Marcaigh A: Esophageal strictures during treatment for acute lymphoblastic leukemia. J Pediatr Hematol Oncol 2010;32: 124-127.

11 Mahboubi S, Silber JH: Radiation-induced esophageal strictures in children with cancer. Eur Radiol 1997;7: 119-122.

12 Cho HJ, Park YS, Kang WK, Kim JW, Lee SY: Thymidylate synthase (TYMS) and dihydropyrimidine dehydrogenase (DPYD) polymorphisms in the Korean population for prediction of 5-fluorouracil-associated toxicity. Ther Drug Monit 2007;29:190-196.

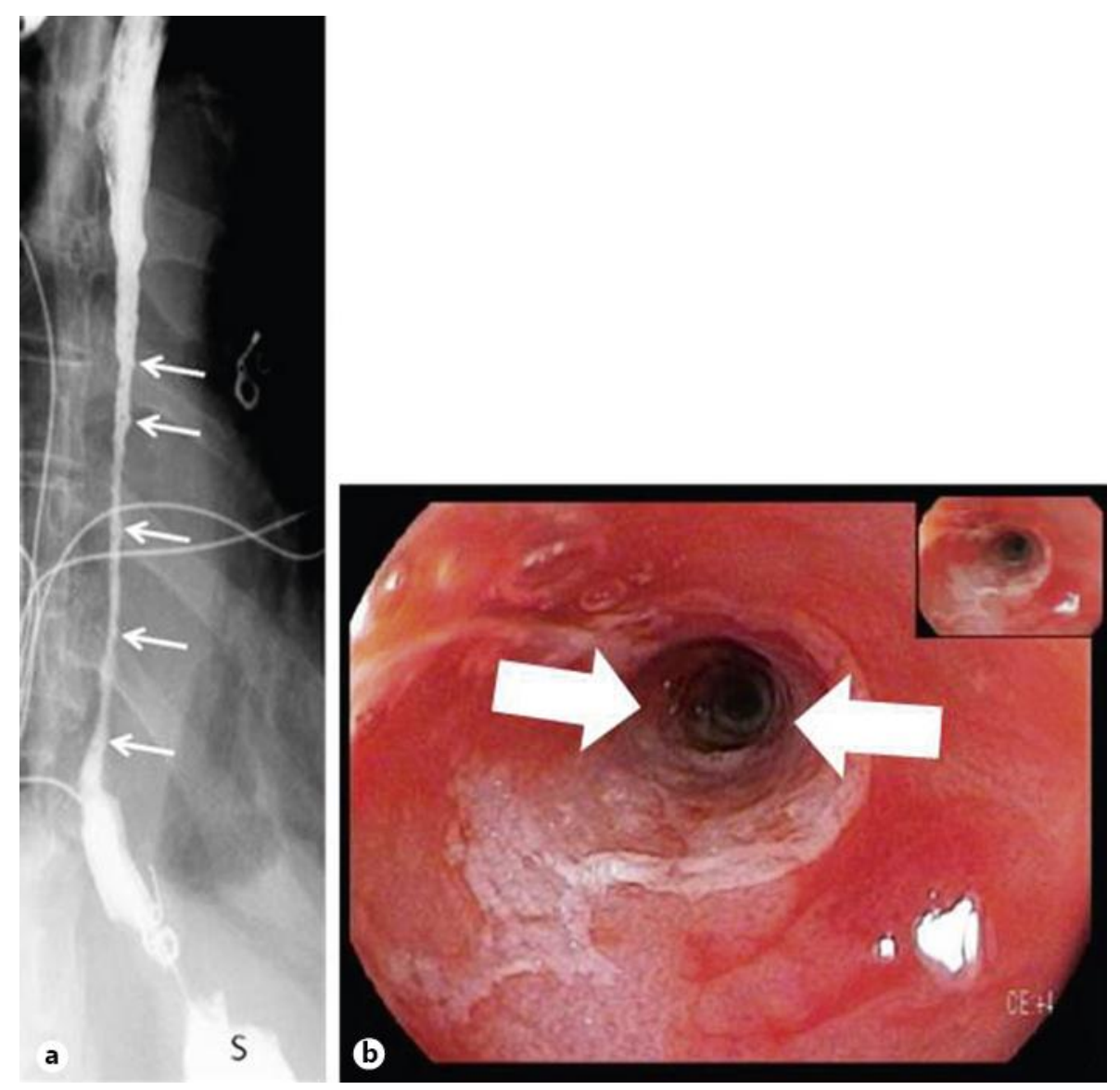

Fig. 1. a Spot image taken during fluoroscopic esophagogram. A long stricture segment $(11 \mathrm{~cm})$ is noted in the mid to distal esophagus with associated mucosal irregularity (arrows). S = Stomach. $\mathbf{b}$ Endoscopic visualization in the middle third of the esophagus demonstrating very friable, erythematous and hyperemic mucosa with a stricture noted $25 \mathrm{~cm}$ from the incisors (between the two arrows). 


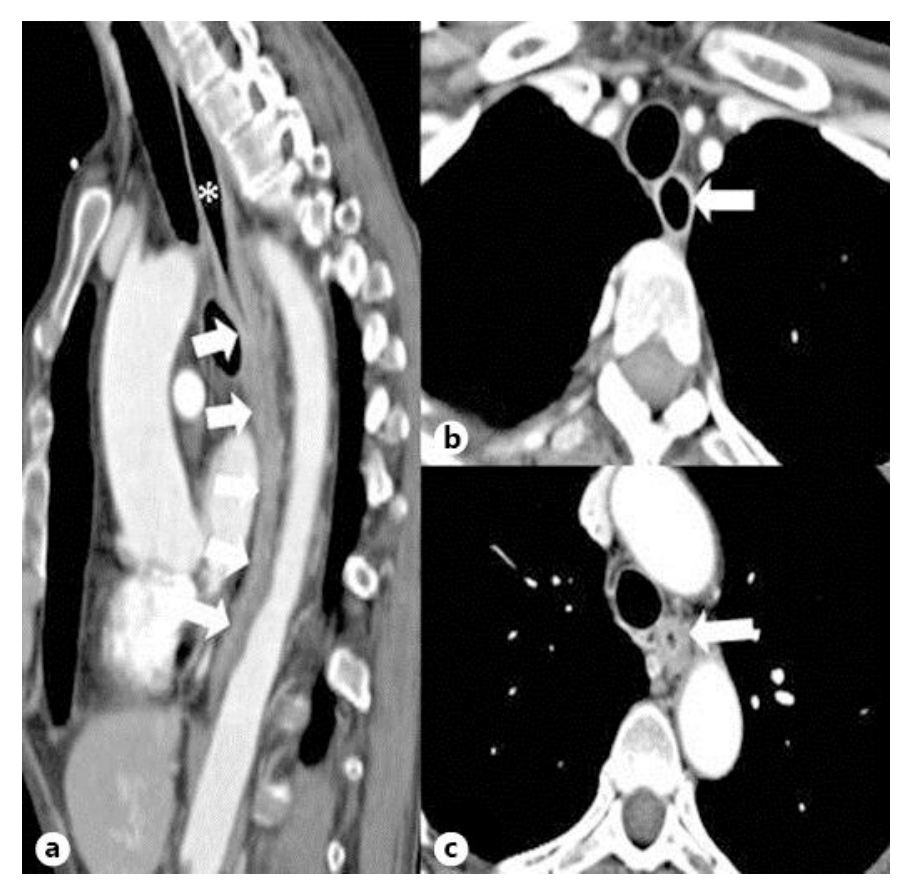

Fig. 2. Contrast-enhanced CT of the chest. a Sagittal reformatted image demonstrating mild distention of the upper thoracic esophagus (asterisk) and long stricture segment of the mid and distal esophagus (arrows). b Axial CT through the upper thoracic esophagus demonstrating normal wall thickness with mild distention (arrow). c Axial CT through the strictured segment showing significant esophageal wall thickening and luminal narrowing (arrow). 